\title{
STUDIES ON FACTORS AFFECTING SUPEROVULATION AND EMBRYO TRANSFER IN HUNGARIAN MERINO EWES
}

\author{
S. $\mathrm{CSEH}^{*}$ and L. SOLTI \\ Department and Clinic of Obstetrics and Animal Reproduction, Faculty of Veterinary \\ Science, Szent István University, H-1400 Budapest, P.O. Box 2, Hungary
}

(Received April 10, 2001; accepted September 5, 2001)

\begin{abstract}
The objectives of this study were (a) to assess the ovulatory response and embryo production of Hungarian Merino ewes after superovulation, (b) to investigate the factors influencing the efficiency of embryo transfer (ET) in Hungarian Merino ewes, (c) to compare the results of two ovarian stimulation protocols (PMSG and PMSG+FSH treatment) in Hungarian Merino ewes, and (d) to study how superovulation, laparoscopic insemination and surgical embryo retrieval (ER) affect the subsequent reproduction of Hungarian Merino donor females after an ET programme. There was no significant difference between the ovarian stimulation protocols in the ratio of donor ewes responding to superovulation nor in the average number of corpora lutea. However, the number of transferable embryos recovered per donor ewe was higher in the PMSG+FSH group. The proportion of transferable embryos, unfertilised oocytes and degenerated embryos did not differ between the treatment protocols. The total pregnancy rate was $53.4 \%$ $(179 / 335)$. Neither the developmental stage of the embryo nor the number of transferred embryos affect the implantation of embryos. However, the increased number of transferred embryos positively influenced the pregnancy rate. No difference was found in the pregnancy rate between synchronised and nonsynchronised groups of recipients. Thirty-six out of 45 donor ewes ( $80 \%$ ) became pregnant within one year after the ET programme, indicating that ovarian stimulation and surgical ER did not affect adversely their reproduction.
\end{abstract}

Key words: Embryo transfer, superovulation, embryo developmental stages, oestrus synchronisation

Embryo transfer in sheep has been used successfully for many years in research. It has been an excellent tool to study the relative importance of genetic and environmental factors on embryo development for years (Moore et al., 1959; Lawson and Rowson, 1972; Brüssow et al., 1999). However, ET also proved to be a very useful tool for importation of breeding animals in the form of frozen embryos especially from remote countries without the risk of transmission of infectious diseases. Hungary imported more than 1000 frozen sheep embryos from

*Corresponding author; E-mail: scseh@univet.hu; Fax: +36 (26) 360-499 
Australia with an implantation rate of $48 \%$ in the early 1980s (Cseh, 1984). The small ruminant husbandry very soon recognised the importance of ET in the genetic improvement, therefore a significant number of commercial sheep ETs has been reported recently (Thibier, 1996). Issues other than economic must be considered in relation to ET in small ruminants; the preservation and multiplication of wild and/or rare breeds could best be served by assisted reproductive technologies, such as ET (Rátky et al., 1997; Solti et al., 2000; Cseh and Solti, 2000; Ehling and Niemann, 2000).

The first ET in sheep was carried out by Warwick and Berry (Warwick and Berry, 1949). The method of embryo recovery (ER) and ET were further developed by Hunter et al. (1955) and Moore and Shelton (1964). The method used is laparotomy because of the anatomical complexity of the cervix. Recently a laparoscopic technique, similar to that used for the insemination of ewes, has been developed and applied successfully (McKelvey et al., 1985a; McKelvey et al., 1985b; Walker et al., 1985; McMillan and Hall, 1994). More recently, nonsurgical transcervical and laparoscopic ER and transcervical ET methods have been developed (Mylne et al., 1992; Buckrell et al., 1993; Flohr et al., 1999) and, although the results are promising, they still must be improved and tested (Cognie, 1999). Transcervical ER and ET has been attempted in the sheep and goat but the recovery and pregnancy rates are still low and highly variable, therefore more work is needed to improve the results before the procedure could be accepted by the practitioners (Flores-Foxworth et al., 1992; Buckrell et al., 1993; McKelvey et al., 1997).

The application of ET in the sheep husbandry is still limited mainly due to the unpredictable ovarian response to the superovulatory treatment and the lack of information concerning factors affecting the efficiency of sheep ET. The objectives of this study were $(a)$ to assess the ovulatory response and embryo production after superovulation of Hungarian Merino ewes, (b) to investigate the factors (e.g. ovarian stimulation, developmental stage and number of embryos transferred, oestrus synchronisation of recipients, etc.) influencing the efficiency of ET technology applied under farm conditions in Hungarian Merino sheep, (c) to compare the results of two different ovarian stimulation protocols (PMSG alone and PMSG+FSH combined treatment) in Hungarian Merino donor females, and (d) to collect data on the reproduction of Hungarian Merino donor ewes after superovulation and ER.

\section{Materials and methods}

\section{Selection of donor females and rams and recipient ewes}

Both donors and recipients were 4-6 years old Hungarian Merino ewes that had lambed in the previous spring. The selection of donor ewes and the rams with which they were mated was performed by the flock owner and the sheep selection specialist of the farm. Embryo donor ewes were ranked by the flock 
owner depending on their lifetime ewe index score and progeny results. The rams were selected on the basis of their wool production (quality and quantity), progeny tests and mating results. The prime determinants in selecting the embryo recipients were a history of (1) settling to first service, (2) no lambing problems, and (3) weaning large lambs at each lambing.

\section{Ovarian stimulation and insemination}

Hungarian Merino donor ewes were randomly allocated into two treatment groups. Each group was exposed to different ovarian stimulation protocols (Table 1). The oestrous cycle of ewes was synchronised by vaginal sponge impregnated with $40 \mathrm{mg}$ Cronolone (Chronogest ${ }^{\circledR}$, Intervet, The Netherlands). The sponges were inserted into the donors for 14 days. In Group $1(n=59)$, ovarian stimulation was induced with 1500-2000 IU PMSG (Folligon ${ }^{\circledR}$, Intervet, The Netherlands) injected intramuscularly (IM) 2 days prior to sponge removal. In Group $2(\mathrm{n}=52)$, a combined treatment of PMSG+FSH was applied. Two days prior to sponge withdrawal 500 IU PMSG and $4 \mathrm{mg}$ FSH (FSH-PR, Burns Biotech, USA) was injected IM, next day the animals were treated with $4 \mathrm{mg} \mathrm{FSH}$ and the following day with $3 \mathrm{mg}$ FSH IM.

Table 1

Ovarian stimulation protocols applied in Hungarian Merino ewes

\begin{tabular}{lll}
\hline \multicolumn{1}{c}{ Day } & Group 1 $(\mathrm{n}=59)$ PMSG & Group 2 (n= 52) PMSG + FSH \\
\hline 0 & sponge insertion & sponge insertion \\
13 & $1500-2000 \mathrm{IU} \mathrm{PMSG}^{*}$ & $500 \mathrm{IU}$ PMSG $+4 \mathrm{mg} \mathrm{FSH}$ \\
14 & - & $4 \mathrm{mg} \mathrm{FSH}$ \\
15 & sponge removal & $3 \mathrm{mg} \mathrm{FSH}+$ sponge removal \\
16 & insemination & insemination \\
$20-22$ & ER & ER \\
\hline
\end{tabular}

*30 IU per kg of body weight

During ovarian stimulation, ewes were inseminated laparoscopically between 30 to $40 \mathrm{~h}$ after sponge removal with fresh or frozen semen. Freshly collected semen was diluted with PBS solution in the proportion of 1 to 3 and $0.2 \mathrm{ml}$ of the diluted fresh semen or $0.2 \mathrm{ml}$ of frozen-thawed semen was directly deposited into the lumen of each uterine horn $\left(20 \times 10^{6}\right.$ motile spermatozoa per uterine horn).

\section{Embryo recovery}

Donor ewes were anaesthetised with a combination of $0.2 \mathrm{mg} / \mathrm{kg}$ xylazine (Rompun, Bayer, Germany) and $10 \mathrm{mg} / \mathrm{kg}$ ketamine hydrochloride (Vetalar, Parke-Davis, USA). The ewes were allowed to stand in the weighing crate in a 
quiet room until recumbent. Embryos were recovered surgically using median laparotomy on Days 4, 5 or 6 after insemination (Day 0). Embryos were obtained from the ipsilateral oviducts and uterine horns if more than two corpora lutea (CL) were found on the ovaries. For ER, Dulbecco's PBS supplemented with $10 \%$ fetal calf serum (FCS) was used to flush the embryos.

\section{Classification, handling and storage of embryos prior to transfer}

Embryos were rinsed in 'fresh' Dulbecco's PBS containing 20\% FCS and stored at $37^{\circ} \mathrm{C}$ for $4-8 \mathrm{~h}$ prior to transfer. Embryos being in a stage of development appropriate for their age were evaluated as viable embryos and transferred into recipients.

\section{Preparation of recipients for embryo transfer; oestrus synchronisation}

The oestrous cycle of recipients was synchronised by insertion of intra vaginal sponge for 13 days and 300 IU PMSG were injected IM at sponge removal. The sponges were removed $12 \mathrm{~h}$ earlier from the recipients than from the donors. A group of non-synchronised recipients $(n=27)$ were also used for ET. Behaviour and oestrus of ewes were stimulated and checked every eight hours by vasectomised teaser rams equipped with crayon-marked briskets.

\section{Embryo transfer}

Embryos were transferred surgically using median laparotomy on Day 4, 5 or 6 after oestrus. Embryos were implanted into the uterine horn ipsilateral to the CL. Generally, one embryo was transferred per recipient $(n=283)$. In 52 cases twin embryos were transferred (one embryo into each uterine horn) per recipient $(n=52)$.

\section{Subsequent fertility of Hungarian Merino donor ewes after ovarian stimulation} and embryo recovery

In order to examine the effect of ovarian stimulation and surgical ER on the fertility of donor ewes, breeding data regarding subsequent fertility (reconception) of 45 superovulated ewes were recorded for 9 to 10 months after the ET programme. Superovulation and ER were carried out both during the breeding season (October) and after that (February). After the ET programme vasectomised teaser rams equipped with crayon-marked briskets were left with the donor females to stimulate and check the oestrous cycle of ewes. Ewes marked by the rams were inseminated. The aims of this data collection were (1) to study how ovarian stimulation with high doses of gonadotropin and surgical ER influence the re-conception of ewes and (2) when the donor ewes could be inseminated successfully after superovulation and ER. 


\section{Statistics}

Standard $\chi^{2}$ tests and analyses of variance were used as appropriate.

\section{Results}

The results of the different ovarian stimulation protocols are summarised in Table 2.

Table 2

The number of corpora lutea and recovered embryos and the quality of embryos obtained in the different superovulation groups of Hungarian Merino donor ewes

\begin{tabular}{|c|c|c|c|c|c|c|c|c|}
\hline \multirow[b]{2}{*}{ Treatment } & \multicolumn{2}{|c|}{$\mathrm{ER}^{+}$} & \multicolumn{2}{|c|}{ Number of CL } & \multicolumn{4}{|c|}{ Recovered embryos } \\
\hline & $\mathrm{n}$ & $\%$ & $\mathrm{n}$ & average & $\begin{array}{c}\text { Transferable } \\
\text { n (\%) }\end{array}$ & $\begin{array}{c}\text { Unfertilised } \\
\mathrm{n}(\%)\end{array}$ & $\begin{array}{l}\text { Degenerated } \\
\text { n (\%) }\end{array}$ & $\begin{array}{c}\text { Transferable } \\
\text { embryos per } \\
\text { donor }\end{array}$ \\
\hline $\begin{array}{l}\text { PMSG } \\
\mathrm{n}=57^{+}\end{array}$ & 42 & 73.6 & 366 & $8.7 \pm 2.0$ & $231(85.2)$ & $25(9.2)$ & $15(5.5)$ & $5.5^{\mathrm{a}}+1.5$ \\
\hline $\begin{array}{l}\text { PMSG+FSH } \\
\mathrm{n}=52^{+}\end{array}$ & 36 & 69.2 & 339 & $9.4+1.9$ & $238(88.8)$ & $17(6.3)$ & $13(4.8)$ & $6.6^{\mathrm{b}}+1.4$ \\
\hline
\end{tabular}

${ }^{+}$Embryos were recovered if more than two CL were found on the ipsilateral ovary. Numbers with different superscripts are significantly different $(\mathrm{p}<0.001)$

There was no significant difference between the two ovarian stimulation protocols. The embryos were recovered from 42 out of 57 ewes in Group 1 and 36 out of 52 ewes in Group 2 (73.6\% vs. 69.2\%). There was also no significant difference in the mean number of CL ( 8.7 vs. 9.4), the ratio of the transferable $(85.3 \%$ vs. $88.8 \%)$ and degenerated embryos $(5.4 \%$ vs. $4.8 \%)$ and unfertilised ova $(9.1 \%$ vs. $6.3 \%)$ between treatments. No difference was found in the ratio of fertilised ova obtained in donor groups inseminated with fresh or frozen semen. However, the average number of transferable embryos was significantly higher in the PMSG + FSH group (5.5 vs. 6.6; $\mathrm{p}<0.001)$.

The pregnancy rate of recipient ewes receiving a single embryo was $51.2 \%(145 / 283)$. Two embryos were transferred into each of 52 recipients, 34 became pregnant $(34 / 52 ; 65.4 \%)$ and 10 lambed twins $(10 / 34 ; 29.4 \%)$. Pregnancy rates were significantly higher when two embryos were transferred (65.4 vs. $51.2 \% ; \mathrm{p}<0.001)$. However, comparing the embryo survival no significant difference was found between the two groups (145/283; $51.2 \%$ vs. $44 / 104$; $42.3 \%)$. 
The pregnancy rates resulting from embryos transferred at 4, 5, or 6 days post-oestrus are shown in Table 3 and indicate that the developmental stage of transferred embryos did not affect embryo survival.

Data on the pregnancy rate of recipients prepared for ET with or without oestrus synchronisation are shown in Table 4.

Table 3

The implantation rates of single embryos being transferred at different ages

\begin{tabular}{cccc}
\hline Age of embryo (day) & Embryos transferred (n) & Lambs born (n) & Survival rate (\%) \\
\hline 4 & 25 & 14 & 56 \\
5 & 17 & 9 & 52 \\
6 & 27 & 14 & 52 \\
\hline
\end{tabular}

Table 4

Pregnancy rates achieved after ET in oestrus-synchronised or non-synchronised groups of Hungarian Merino recipient ewes

\begin{tabular}{lcccc}
\hline & \multicolumn{4}{c}{ Number of recipients } \\
\cline { 2 - 4 } & transferred & & \multicolumn{3}{c}{ pregnant } \\
\cline { 2 - 4 } \cline { 4 - 5 } & (n) & & (n) & $(\%)$ \\
\hline Non-synchronised & 27 & 18 & 55.5 \\
Synchronised & 44 & 26 & 59.1 \\
\hline
\end{tabular}

No significant difference was found in the pregnancy rate between the synchronised (S) and non-synchronised (NS) groups of Hungarian Merino recipients. Eighteen out of $27 \mathrm{NS}$ and 26 out of $44 \mathrm{~S}$ recipients became pregnant (55.5\% vs. $59.1 \%)$.

Eighty percent of the donor Hungarian Merino ewes (36/45) became pregnant, giving birth to 44 lambs within one year after the ET programme. Twelve ewes out of 45 remained pregnant $(12 / 45 ; 26.6 \%)$ and lambed 15 lambs, although the uterine horns were rinsed with culture medium. Twenty-four donors $(24 / 45 ; 53.3 \%)$ showed oestrous signs and were successfully inseminated within four months after the ET programme, and 29 lambs were born.

\section{Discussion}

Superovulation is still the most neuralgic point of ET technology determining the result of an ET programme in every species. A high degree of variability in ovulation rate in response to superovulation has been demonstrated 
again. Similarly to the bovine species, the great variability in ovarian response to the ovarian stimulation treatment is the main limiting factor of ET in small ruminants (Seidel and Seidel, 1991; Cognie, 1998). Embryo production from superovulated ewes is hindered by an unpredictable response to hormonal treatment. Progress in this area should be expected of an appropriate control of follicular development with gonadotropin-releasing hormone $(\mathrm{GnRH})$ agonist or antagonist prior to gonadotropin administration (Jabbour et al., 1991). There are several factors, such as breed and age of donors, gonadotropin and ovarian stimulation protocol applied, stage of the ovarian cycle (i.e. size of follicles present on the ovary when stimulation is started), nutrition, housing and keeping conditions (i.e. management), etc., that contribute to the variability of the ovarian response to superovulation (Moore et al., 1959; Lawson and Rowson, 1972; Betteridge, 1977; Armstrong and Evans, 1983; Boundy et al., 1985; Brebion et al., 1992; Crosby, 1993; Evans et al., 1994; Fernie et al., 1994; Vivanco et al., 1994; Gordon, 1997; Bunch et al., 2000).

The variability observed in the percentage of embryos of transferable quality is mainly influenced by the breed (Betteridge, 1977; Shelton et al., 1982; Armstrong and Evans, 1983; Boundy et al., 1985; Vivanco et al., 1994). Armstrong and Evans (1983) superovulated three different breeds of sheep (Suffolk, Australian Merino and Romney Marsh) and, comparing the responses, they observed significant differences in the ovulation rate and embryo yield between breeds. The highest mean ovulation rate $(16.6 \pm 3.7)$ was found in the Merino group and the lowest $(8.2 \pm 2.0)$ in the Romney Marsh. However, the highest incidence of fertilisation failure, which resulted in a lower mean number of embryos transferred per donor, was also observed in the Merino group (Suffolk $5.2 \pm 0.7$; Romney Marsh $3.8 \pm 1.5$; Merino $2.9 \pm 1.4$ ). In contrast, we observed lower ovulation rate but better fertilisation rate in Hungarian Merino which resulted in a higher mean number of transferable embryos per donor (5.5 \pm 1.5 and $6.6 \pm 1.4)$ in both treatment groups. In our study, fertilisation failure did not appear to occur, perhaps because of the laparoscopic intrauterine insemination applied. Following vaginal or cervical insemination, fertilisation rates in the high responders are low, even after 2 or 3 inseminations, supposedly due to the reduced cervical transport of spermatozoa. Thus, high fertilisation rates could be achieved only if the semen is deposited directly into the uterine horns (Trounson and Moore, 1974; Evans and Armstrong, 1984). Superovulating Spanish Merino ewes with FSH (FSH-P and FSH-O), Gonzales et al. (2000) obtained slightly lower ovulation rate $(6.3 \pm 1.9$ and $7.0 \pm 1.7)$ than that of the Hungarian Merino stimulated with PMSG or PMSG+FSH (8.7 \pm 2.0 and $9.4 \pm 1.9)$.

The gonadotropin and stimulation protocols used are also major factors determining the quality of ovarian response to superovulation. Since FSH preparations became available the efficiency of PMSG and FSH has been studied in comparative experiments. FSH is reported to be superior to PMSG in terms of 
ovulation and fertilisation rates and in the production of good-quality embryos in all species (Armstrong and Evans, 1983; Seidel and Seidel, 1991; Gordon, 1997; Cognie, 1998). Using PMSG for ovarian stimulation under practical conditions, Boundy et al. (1985) obtained disappointing response to superovulatory treatment in Texel ewes. The major problem encountered was the variable and generally poor response to injections of PMSG. Comparing the results obtained with PMSG or FSH, Armstrong and Evans (1983) found that FSH more consistently resulted in increased ovulation rate with lower incidence of excess large follicles, which failed to ovulate, than PMSG. Further, the variance in ovulation rate tended to be greater in response to PMSG than to FSH, and a lower percentage of all donors treated with PMSG than FSH yielded embryos suitable for transfer. Using FSH-P and FSH-O for superovulation of ewes during the reproductive season, Riha and Cunart (1999) found no difference between the treatments. Our results support the observations that ovarian stimulation protocols into which FSH is incorporated yield higher number of viable embryos. The number of transferable embryos per donor ewe was higher in the group of Hungarian Merino donor females treated with PMSG+ FSH. Naqvi and Gulyani (1999) obtained similar results with Rambouillet ewes as we did with Hungarian Merino. They superovulated the ewes with different gonadotropic hormones under semiarid conditions and found that Rambouillet sheep can be effectively superovulated for embryo production with FSH-P or with the combination of PMSG and FSH-P. However, the ovulation rate was lower in the Rambouillet ewes than in the Hungarian Merino ones.

No differences were found between the implantation rates of embryos transferred at various ages. Further, no difference was found in the embryo survival rates (number of lambs born) of groups having single or twin embryo transfers. Our result support the data obtained by Riha and Cunart (1999) who observed that the increasing number of transferred embryos (up to 3) was associated with an increasing number of lambs, however a negative tendency was evident in the embryo survival. In our study, the number of implanted embryos did not improve the embryo survival rate, however, the twin transfers increased the pregnancy rate of the recipients. Therefore, decisions on numbers of embryos to be transferred per recipient should be based on the numbers of recipients available, and assessment of a given recipient's probable ability to carry and raise twin lambs.

No difference was obtained in the pregnancy rate of synchronised and nonsynchronised recipients, indicating that oestrus synchronisation does not affect adversely embryo survival after transfer. However, using oestrus synchronisation the organization of the sheep ET became easier and the number of recipients initiated into the programme may be decreased, resulting in a reduction of expenses.

The effect of the collection technique used to retrieve the embryos from the superovulated Hungarian Merino ewes on their subsequent fertility after col- 
lection was monitored over a period of 9 to 10 months. In a similar study comparing different ER techniques (surgical vs. laparoscopic vs. control/not used in ET programme), Naqvi et al. (2001) found a significant difference in mating per pregnancy between the different techniques. Their conclusion was that the surgical technique of embryo collection adversely affected the fertility of donors. However, our data indicate that high fertility $(80 \%$ fertilisation rate, $98 \%$ lambing rate) can be maintained even after surgical embryo collection. It was remarkable that 12 ewes out of $45(26.6 \%)$ kept pregnancy originating from superovulation in spite of the fact that the uterine horns were rinsed with culture medium. Our results show that superovulation and surgical intervention performed carefully did not affect adversely the subsequent fertility (re-conception) of the donor ewes following an ET programme.

In summary, it can be said that Hungarian Merino ewes can be effectively superovulated and ovarian stimulation applied under farm conditions can result in the production of a high number of good-quality embryos, which can be transferred into recipients with good implantation rate. However, there are several factors (e.g. breed, ovarian stimulation protocol, management, etc.) that are responsible for the variability of the ovarian responses and implantation rates of embryos. A number of recent advances in ET technology applied in small ruminants have improved the application of this technique to commercial breeding programmes. ET is a very useful tool to improve the genetic capability of a breeding flock.

\section{References}

Armstrong, D. T. and Evans, G. (1983): Factors influencing success of embryo transfer in sheep and goats. Theriogenology 19, 31-41.

Betteridge, J. J. (ed.) (1977): Embryo Transfer in Farm Animals. A Review of Techniques and Applications. Canada Department of Agriculture. Monograph 16, 1977.

Buckrell, B. C., Gartley, C. J., Buschbeck, C., Jordan, P. and Walton, J. W. (1993): Evaluation of a transcervical AI technique for transferring embryos in sheep. Theriogenology 39, 197 (Abstract).

Boundy, T., Clarkson, J. M. and Winter, C. A. (1985): Embryo transfer in sheep under practice conditions. Vet. Rec. 117, 379-381.

Brebion, P., Baril, G., Cognie, Y. and Vallet, J. C. (1992): Embryo transfer in sheep and goat. Ann. Zoot. 41, 331-339.

Brüssow, P., Rátky, J., Torner, H., Sarlós, P. and Solti, L. (1999): Contribution of porcine follicular fluid in the process of fertilization in vivo. Reprod. Dom. Anim. 34, 139-145.

Bunch, T. D., Panter, K. E., Wang, S., Evans, R. C. and Holyoak, G. R. (2000): The effects of three dosing regimens of gonadotropins on sheep superovulation. Theriogenology 53, 494.

Cognie, Y. (1998): State of the art in sheep-goat embryo transfer. Theriogenology 51, 105-116.

Crosby, T. F. (1993): Superovulation in sheep: the effects of pFSH type and ewe breed. Theriogenology 39, 205.

Cseh, S. (1984): Successful transfer of deep-frozen sheep embryos. International Symposium on Sheep Production on Big Farms, Debrecen, Hungary, Aug. 14-16. C. pp. 207. 
Cseh, S. and Solti, L. (2000): Importance of assisted reproductive technologies in the conservation of wild, rare or indigenous ungulates: review article. Acta Vet. Hung. 48, 313-323.

Ehling, C. and Niemann, H. (2000): Establishment of embryo banks to maintain endangered sheep breeds. Züchtungskunde 72, 140-152.

Evans, G., Maxwell, W. M. C. and Wilson, H. R. (1994): Superovulation and embryo recovery in merino ewes. Theriogenology 41, 192 (Abstract).

Evans, G. and Armstrong, D. T. (1984): Reduction of sperm transport in ewes by superovulation treatments. J. Reprod. Fertil. 70, 47-53.

Fernie, K., McKelvey, W. A. C. and Dingwall, W. S. (1994): Endogenous FSH concentration in the ewe is not correlated to superovulatory response. Theriogenology 41, 194 (Abstract).

Flores-Foxworth, G., McBride, B. M., Kraemer, D. C. and Nuti, L. C. (1992): A comparison between laparoscopic and transcervical embryo collection and transfer in goats. Theriogenology 37, 213 (Abstract).

Flohr, S. F., Wulster-Radcliffe, M. C. and Lewis, G. S. (1999): Technical note: development of a transcervical oocyte recovery procedure for sheep. J. Anim. Sci. 77, 2583-2586.

Gordon, I. (1997): Controlled reproduction in sheep and goat. CAB International, 1997.

Hunter, G. L., Adams, C. E. and Rowson, L. E. (1955): Inter-breed ovum transfer in sheep. J. Agric. Sci. (Camb.) 46, 143-149.

Gonzales, B. A., Santiago, M. J., Cocero, M. J. and Lopez, S. A. (2000): Effects of FSH commercial preparation and follicular status on follicular growth and superovulatory response in Spanish Merino ewes. Theriogenology 54, 1055-1064.

Jabbour, H. N., Ryan, J. P., Evans, G. and Maxwell, W. M. C. (1991): Effects of season, GnRH administration and lupin supplementation on the ovarian and endocrine responses of $\mathrm{Me}-$ rino ewes treated with PMSG and FSH-P to induce superovulation. Reprod. Fert. Dev. 3, 699-707.

Killeen, I. D. and Caffrec, G. J. (1982): Uterine insemination of ewes with the aid of a laparoscope. Aust. Vet. J. 59, 95-98.

Lawson, R. A. S. and Rowson, L. E. A. (1972): The influence of breed of ewe and offspring on litter size after egg transfer in sheep. J. Reprod. Fertil. 28, 433-439.

McKelvey, W. A. C., Robinson, J. J., Aitken, R. P. and Henderson, G. (1985a): The evolution of a laparoscopic insemination technique in ewes. Theriogenology 24, 519-524.

McKelvey, W. A. C., Robinson, J. J. and Aitken, R. P. (1985b): A simplified technique for the transfer of ovine embryos by laparoscopy. Vet. Rec. 117, 492-494.

McKelvey, W. A. C., McEvoy, T. G., Dingwall, W. S., Robinson, J. J. and Lindsay, E. (1997): The use of exogenous hormones to facilitate transcervical embryo recovery in sheep and their effect on embryo development. Theriogenology 47, 369 (Abstract).

McMillan, W. H. and Hall, D. R. H. (1994): Laparoscopic transfer of ovine and cervine embryos using the transpic technique. Theriogenology 42, 137-146.

Moore, N. W. and Shelton, J. N. (1964): Egg transfer in sheep. Effect of degree of synchronization between donor and recipient, age of egg, and site of transfer on the survival of transferred eggs. J. Reprod. Fertil. 7, 145-150.

Moore, N. W., Rowson, L. E. A. and Short, R. V. (1959): Egg transfer in sheep. Factors affecting the survival and development of transferred eggs. J. Reprod. Fertil. 1, 332-359.

Mylne, M. J. A., McKelvey, W. A. C., Fernie, K. and Matthews, K. (1992): Use of a transcervical technique for embryo recovery in sheep. Vet. Rec. 130, 450-451.

Naqvi, S. M. and Gulyani, R. (1999): Ovarian response and embryo recovery to different superovulatory regimens in Rambouillet ewes under semi-arid conditions. Small Rumin. Res. 34, 127-131.

Naqvi, S. M., Joshi, A., Das, G. K. and Mittal, J. P. (2001): Development and application of ovine reproductive technologies: an Indian experience. Small Rumin. Res. 39, 199-208. 
Rátky, J., Treuer, Á., Szabó, P., Döbrentei, B., Soós, F., Seregi, J., Solti, L. and Brüssow, K. P. (1997): Propagation of an endangered swine breed by laparoscopic embryo transfer. Theriogenology $47,405$.

Riha, J. and Cunart, L. (1999): Superovulation, embryo yield, quality and embryo transfer in sheep. Czech J. Anim. Sci. 44, 19-24.

Seidel, G. E. and Seidel, S. M. (1991): Training Manual for Embryo Transfer in Cattle. FAO Animal Production and Health Paper. Rome, 77 pp.

Shelton, J. N., Trounson, A. O., Moore, N. W. and James, J. W. (eds) (1982): Embryo Transfer in Cattle, Sheep and Goats. Australian Society for Reproductive Biology, pp. 35-46.

Solti, L., Crichton, E. G., Loskutoff, N. M. and Cseh, S. (2000): Economical and ecological importance of indigenous livestock and the application of assisted reproduction to their preservation. Theriogenology 53, 149-162.

Thibier, M. (1996): Statistics of the ET industry around the world. IETS Newsletter 15, 10-13.

Trounson, A. O. and Moore, N. W. (1974): Fertilization in the ewe following multiple ovulation and uterine insemination. Aust. J. Biol. Sci. 27, 301-304.

Vivanco, H. W., Greaney, K. B. and Varela, H. (1994): Explaining the variability in superovulation responses and yield of transferable embryos in sheep embryo transfers. Theriogenology $\mathbf{4 1}$, 329 (Abstract).

Walker, S. K., Warnes, G. M., Quinn, P., Seamark, R. F. and Smith, D. H. (1985): Laparoscopic technique for the transfer of embryos in sheep. Aust. Vet. J. 62, 105-106.

Warwick, B. L. and Berry, R. O. (1949): Inter-generic and intra-specific embryo transfers in sheep and goats. J. Hered. 40, 297-303. 